\title{
ANTICIPATING A FLUID, DYNAMIC INTERIORITY
}

\author{
ANDREW FURMAN \\ Ryerson School of Interior Design, Ryerson University, Canada.
}

\begin{abstract}
This paper will explore some ideas regarding variations in the nature of the public and private realms that are speculative in nature yet based in studies of shifting patterns of how streets are used and experienced. It is equal parts anticipation and reflection.

Fundamental to this investigation is a reassessment of what is meant by the term the interior, and how it has been changing this past century through significant advances in technology and redefinitions of mobility. Advances in mechanization and the evolution of early 20th century streets provided an environment for a changing dynamic interiority in the city.

Investigating a dominant arterial in the centre of Toronto, the changing pattern of a few qualities will be examined and then speculated upon regarding some imminent changes to the flows and patterns of use regarding the streetscape, such as the changing nature of shop fronts along a streetscape- that I refer to as a shop front interiority, as well as the changing role of the street front due to, for example, an influx of density from new developments, wireless connectivity, and our near-future of sharing space with drones and autonomous vehicles. From this examination of the shifting nature of the affordances found in what was a more static street front, a different version of a sustainable urban life of the street is imagined.

The combined factors of a changing street scape will lead to new patterns of use that will impact upon ideas of interiority through the ways that we think about and use this new shifting realm of an extended private realm in the public.

Keywords: affordances, anonymity, autonomous vehicles, display windows, glazing, Interiority, mobility, privacy, public realm, public space design, streets, technology, the interior.
\end{abstract}

\section{INTRODUCTION}

This paper considers the shift in public and private and the reassessment of what we mean by the term the interior. Building a greater understanding about the shifting scope of a field such as interiors to include a plural interiority necessitates a loosening of the preconceptions surrounding the design of the private realm and how this zone of space is in a dialectical relationship with the public realm and the spatial opportunities that are part of the emerging advances of AV (autonomous vehicles); for the purposes of this paper AV will mean no driver, only passengers. Historian Brian Ladd points out that with traditional cars 'what seems to be hardly noticed or commented on is that the price of rapid door-to-door transport on demand is the almost total surrender of personal freedom for most of the journey' (my italics) [1]. Our collective, on-going layering of the overall connected networks of data gathering analytics is a new era of the public realm. How our privacies and public mobility will be affected by this convergence will be introduced and speculated on in the context of an expanded zone of interior interactive space.

\section{INTERIORS TO INTERIORITY WITH AV (AUTONOMOUS VEHICLES)}

To begin let us define what is meant by the term the interior. In spatial terms the interior means a place that is separate from the publicness of the out of doors, or the urban physical space of encounter in a city, in modern circumstances. Some implicit affects of interiors practice are in need of reassessment if we are to sketch out a range of opportunities for a more sustainable, polyvalent practice to emerge. Interior practice's scope has been unfortunately misunder- 
stood-some saw it as an accessory, a peripheral element of fashion perpetually tied to consumer styling trends through mimicry of a hyphenated modernity-this is in need of revision if a conversation about the role of interiors in a sustainable city context is to occur. We might ask what advances in technology coupled with a relaxing of the definition of interiority, will yield a broadened scope of interior agential performance? Penny Sparke reflects on how the mass media packages interior work and interiors practice as something idealized and an 'object of desire' [2] and that this has been going on since the late Victorian era, continuing with gusto as seen in the media in popular contemporary home and restaurant renovation television programs. Neil Leach reminds us that mimicry and camouflage have been strategies for fitting into society by all, and it represents a powerful means of communication that uses elements of fashion and ones microenvironment, even though it might appear to be an act of individual expression, it is also a 'collective behaviour' used by all living things [3]. The aesthetic dimension of environments defined as fashion and aesthetics has, as pointed out by Designer Otl Aicher, almost everything to do with architecture and products-and by extension, this also applies to interiors and the shaping of space, where the 'best way to conceal power is still by aesthetics' [4]. How we use our interiors reveals much about how we act in all spaces.

Scientific advances especially in the past century have enabled us to question the transitions between the inside and outside worlds and the public realm. The futurist architect, Sean Lally reminds us that it was largely in the nineteenth century that the term interior began to mean the inside of a building or room, whereas prior to this, interior referred more to one's individual spiritual and moral character and not necessarily a physical space [5]. Coincidentally, this conception of a hardening between two spaces grew at the same time as the advent of air-conditioning, first in factories and then adapted to other spaces, making them all by definition, interiors. The proto-modern sensibility of the hermetically-enclosed building was first a technical requirement that protected the machines' moving parts used in factories and also kept products in a state of equilibrium by maintaining a constant set temperature for the early mass produced items such as processed foods to prevent their spoilage.

Interiors practice adapts the existing environment to suit the needs of the users of the space. This has been occurring before the splintering of the disciplines from master builder to architect and engineer 200 years ago, to the many professions, most recently with Interior Designers and Urban Planners with more divisions yet to come. Traditionally, 'the shapes of buildings are a response to the outer boundary of the human body for calibrating proportion and scale' [6]. Spatial programming, the diagramming out of functions and movements, was ready to incorporate technological improvements that would build on the space planning concepts and apply them to modern life. The Historian Siegfried Giedion describes the early programming and space planning of manufacturing spaces and the workers that promoted Taylorist efficiency to the factory [7]. The programming of space with technology thus continued to evolve in pairings through the modernization of places of work and leisure. For example, the latest furnishings and appliances were introduced into the home; in the shops, large plate glass displays of merchandise were choreographed to entice a leisure-time focused public; specific office furniture and layouts were developed for office staff; public interiors were developed for full-service experiences within hotels, cafes, and restaurants were designed to comfort a growing class of patrons. Interiors, like mobility itself is a polymorphous evolving term, relating to a sense of actions connected to a state of being. The birth of the design of interiors has made do with the technology that was at hand, adapting it to maintain the events occurring within it. Giedion's history of mechanization: Mechanization Takes Command, describes how the pursuit of timesaving mechanized inventions and 
buildings such as the automatic milling machines designed by Oliver Evans of Boston through to the assembly lines perfected by Henry Ford in Detroit compelled us to embrace speed and functionality [8]. Mark Kingwell reflects on the positivity of technology across different eras, building from the industrial revolution's products to the designed objects in current production. Kingwell notes the sense of 'mechanistic nineteenth-century optimism of it all' [9] that was tied to a notion of progress that is made complicated for us today by our growing awareness about the complexity of the issues and ideas surrounding sustainability and progress.

Interiors work seeks a temporal solution to the multitasking needs between the role of function + social dimension. The function might be to perform a task or chore more efficiently, and thereby allowing for more time to pursue the social relationships of family, work, or acquaintances. This simple duality of one's wanting more free time to be rid of laborious hand-work through automation in the places of work, and in the home and public realm, has morphed in recent decades to a mobility-enhanced media convergence of communications data [10] creating a growing, global emergent networked landscape that blurs and stacks leisure, work and information. Here are two common examples of the blurring of spaceusing the free time while on a train to finish a report for work, or two people watching a downloaded film on a tablet while taking a long airplane trip. The interior and what is an activity in the public realm, has quite simply been recast because of technology.

The terrain of personal space has changed significantly since Anthropologist Edward T. Hall defined the spatial bubbles that defined one's zones [11] from intimate distance to a publicly-occupied one whereby behaviours were clearly established in the cultural milieu that one found oneself physically in. Edward T. Hall could not have anticipated the increased social distances created through the internet and wireless technology between people compared to when he developed the emergent field of proxemics in the early 1960's but he probably would have continued his thoughts that 'increased social distance is now remaking social and political institutions' in novel ways [12]. Hall's pioneering research about the four distinct spatial zones from the intimate space of a few inches to the public zone (anywhere from 12 to $25 \mathrm{ft} . / 3.6$ to $7.5 \mathrm{~m}$ or more) is now complicated by the use of mobile phones that alter the relational aspects of strangers and those close to us by adding another spatial zone of communications technology-'a membrane of privilege' [13], in to the proxemical zones. Ever since the mobile phone began to be represented in popular films, first as a connected phone in an automobile interior with Sabrina (Wilder, 1954 [14]) as a temporary withdrawing device from the public realm, it is clear that Hall's bubbles of space have been modified with a more fluid, dynamic sense of space concerned with capsular movements. Without any particular policy, the public adapted this new form of mobility rapidly-the tools extended our reach with ease through speed. The advances of a fleet of integrated software and sensing equipment coupled with machine learning have brought the autonomous vehicle closer to an everyday reality. The AV is another step in the public's acceptance of proxemical and social-spatial changes if it provides some significant improvements to one's daily routine. As we have seen, the 'adoption of the motorcar introduced the idea of democratic mobility' [15]. Hall's idea of extension transference, that is, a technology that is dependent on the human actor for its functioning, and not acting independently as an active agent, is quickly being reconsidered with AV [16]. The car has been used as much more than a transport device in popular film and print. It has been referred to as a mobile interior, and as an extension of one's own living space. Advertising has promoted the automobile as such and it seems to be in a state where it has assumed the guise of an old building-a shell for which new (interior) activity will give it an extended life with the advent of AV. 
Moving forward with sustainability as a goal, the view held by Sociologist Richard Sennett is that our current era is a 'fantastic (electronic) revolution' but that 'our problem is not machines but how we use them.' Sennett seeks to understand our humanity with technology in examination of craftwork and human processes [17]. AV's will likely further delaminate the traditionally understood architecture, interiors and public space as we relearn how to behave in a technologically enhanced world. If the public adopts this post-zoned space of different micro-spatialities, it will help liberate interiority from a configuration of rooms and circulation to an augmented sphere that will be more about sensing and enhancing connections beyond walls and the volumes with environmental performativites in the very walls themselves and body enhancements (chemical, internal and external augmentation) [18] coupled with advances in AV's (electrical power or other) will create the need for new models of home-work-mobility, further blunting the boundary between the workplace and privacies even further.

Ultimately the successful adoption of mobile extensions of work and home will depend on the integration of the new model of mobility into the existing patterns of use and movement. If $\mathrm{AV}$ and the possible changing patterns of convenience for the public proves itself to be a major disruptive force to existing industries and to integrated patterns of behaviour such as the transportation industry (i.e., freight, public transit, private automobile ownership and use) then it will be a new era of prediction for us to imagine how the street might be reprogrammed for the public. Parking space, and the idea of parking a private vehicle itself might be a thing of the past as the vast spaces given over to parking would morph into new street uses from the porosity of choices that will be coming from the pods, fleets, transports, and AVtaxis [19]. Adapting to these fundamental shifts in how we flow our goods and selves will be as disruptive as the last century was when the motorcar was made affordable for the general public, as it transformed entire plans and the circulatory systems of cities and outlying areas.

The idea of an interior whether it is public or private, has much to do with the exposure of a larger imagined site as stated in Robert Smithson's writings about revealing spaces that are sites in his work. He writes 'one does not impose, but rather expose the site be it interior or exterior. Interiors may be treated as exteriors or vice versa' [20]. This speaks to a fundamental shift in the nature of interiors, that it (space) and we are now always a part of the publicness of a virtual public realm. An inter-changeability of boundaries is expressed by Slavo Žižek who finds the altering of a device such as an operable window, whether in a car or building to dramatically alter ones relationship, affects how one feels about being a part of the overall scene [21] that is, the exterior. It is said to be a place the average American inhabits about only $7 \%$ of their time in a week [22]. 'One perceives the reality outside (a car window) in a weirdly derealized state, as if one is watching a performance on a screen; when one opens the window, the direct impact of the external reality always causes a minimal shock; we are overwhelmed by its proximity' [23].

There are technologies that are in their infancy today that have the power to alter interior space to the same extent that the elevator and escalator have done to alter forever how we view the tall and large building, and equally, what asphalt and concrete have done to the centre, (in its original use asphalt was for the comfort of bicycles [24]) to transform forever the idea of a definable edge of the traditional city. This is 'unplanned technological innovation' [25]. In these three examples, all share the common problem that was overcome by the technological design-transferring the human body across space in a comfortable manner. Importantly, up until recently, these technologies of mobility did not add another activity to the primary user to benefit from the comfort zone of not being active. In a sense the concept 
of these devices of mobility sped up the journey but the active agent was in a sense, passive. The current era promises to add a new performativity and social dimension to all these mobility-assisted spatialities; vertical, diagonal and horizontal movement systems now have ubiquitous contact to others. Looking at the bottleneck of enhancements, the elevator and escalator are trapped on a track, in one vector, like the train they cannot alter course or be freed from their path, so the maximum use-value has already been programmed into the $100+$ storey towers and in the reverse-directions of escalators that switch depending on the rush hour scenario in transit facilities, for example.

Interiors, streets and technology promise an on-going re-claiming of circulation in space because, like the streets and routes of the system as it exists, the flexibility of the spatial-architectural system is always in a state of 'becoming' and adaptable to many influences, and unfinished, like the act of writing itself [26]. Older building stock and small spaces, readily available, will be adapted.

Penny Sparke reminds us of the possible push/pull potential of interior/exterior integration as demonstrated with the furniture designs of the Eames' whereby the design occupies either inside or outside depending on the weatherability of the surface treatment (fabric, fibreglass etc.) on the contact points with the body [27]. In terms of scale, Sparke discusses the film The Truman Show's (Weir, 1998) radical notion of inside/outside separation through technologically modifying the environment to simulate both conditions, which creates a disturbing feeling because the interior scale is too vast for our understanding of interior to still hold [28]. Similarly, Hall's mention of cocooning that occurs within automobiles was a warning about being too dependent on a technology; cars were 'cutting (people) off from the outside world' [29]. Our desire for a private bubble had consequences without any active agency. Jeffrey Reiman defines privacy as 'the condition in which others are deprived of access to you' through spatial affects such as locks, curtains, and doors [30]. The privacy ramifications between human and AV agency will be tremendously important to navigate as we either choose to relinquish more of our private selves for greater ease in a state of near total mobility, or resist and accept fissures between modes of travel and the digital world.

One might ask how does a redefinition of mobility tie into the redefinition of interiority? In the early stages of mobility (mobile phone and internet) from about the mid 90's-perhaps not too much as the technology wasn't yet saturated into the public sphere and it was still too rudimentary in terms of interface. But now, and into the next decade, redefinitions of once strong spatial separators such as the suburbs and the place of work in the urban core are being patched with in-between zones, third places, and something that feels urban yet might not look like it yet. The surge of communications data and media will change the 'relationships with time and space' [31]. As in an idealized model of New York city, where pedestrians and taxi's determine all the patterns, AV suggests a becoming-urban everywhere. Rem Koolhaas wrote prophetically about the relationship between driving or being driven and plannings' good intentions; the vagueness of what this feeling is for an authentic, engaged urban experience- '( $\mathrm{t}$ )he word urbanism which somehow suggests a minimum of steering' [32].

\section{STREET REWRITE. WHAT-IF NO MORE PARKING OR CONGESTION?}

Streets are the corridors of the city's rooms and direct all the main movement that architecture and that the public realm connect into. Streets concretize the choice of movement in the city. Revisiting some key features of early streets demonstrates that the street features provided an environment for a changing dynamic interiority in the city. In the urban context innovations and inventions led to policy and standards adopted by the public. Since 'most of 
our daily life is governed by social conventions' [33], there is a correspondence between the spaces we make and how we use them.

'(G)lass represented the potential liberation of interior space, the reintegration of the interior with its exterior setting,' writes Scott Murray on the transformation of the street context through the early large-scale commercial buildings that have adopted the iron and steel rigid frame, and as a consequence the availability of large plate glass that became the curtain wall. This thinking about liberation from the past was paramount in designers' minds such as F. L. Wright [34] who extolled the virtues and freedoms of the new buildings walls' transparency and to compliment this fixity, the freedom, both as vector and aesthetic that the motorcar gave to the driver in order to conquer space. The look out and the gaze in of shop fronts and convertibles, led to different applications of glass that defined our world of infinite reflections of strangers and ourselves. The tinting of glass is something that has developed more recently and it can be seen to be a standard defensive feature of most private vehicles. Interestingly however, larger commercial trucks and maintenance vehicles still predominantly use clear glass-working symbolically as a task-oriented space, the driver communicates work and safety to the public. The tinting of glass is another camouflage technique that cocoons the driver and passenger from point $a$ to $b$ much in the way that court-carriages used to do [35] and that has been adopted as a means of critiquing the power of the architectural gaze in the work of the Artist Dan Graham through 1-way mirror glass that exploits reflections and transparency between individuals on either side [36].

The sidewalk or footway is a contemporary adaptation to sociable public space that suited the slow moving pedestrians along the edges of streets, controlling behaviour in a Foucauldian manner that also announces our willingness and capacity to be disciplined at the height of the public adoption of the motorcar in the city. Signalized intersections and the control of flows of traffic is a complex network of algorithms in a large city that deal with the multiple congestion events of motor vehicles. Events such as the relaxing of Sunday shopping [37] and the prominent role shopping has in today's virtual and physical urban environment is a continuation of the street yet paradoxically not of the street. All these urban adaptations related to the car, shopping and the street. Sze Tsung Leong writes that the success of a busy shopping environment and its sales 'has made the relationship between shopping and urbanism indistinguishable from the issues of mobility' [38]. It may be that the next era of urban adaptation might be the fluid movement exchange of online-AV-pedestrian shopping. This may be the promise of an AV-enhanced culture that greatly expands what the urban and public realm may become (beyond shopping, for instance).

The example of Yonge St. in Toronto, a narrow yet central street in the city shows in early maps from a century ago how the street blocks running north/south were filled with an average of eighteen shop fronts per short street block in the 1890's [39]. There are now on average 2 to 4 buildings in the same block, a generic large, lumpen mass self-effacing in its overscale towards pedestrians. The shop front interiority-that is, the gaze and glow of the interior thru to the exterior, especially in the evening, gave direct access of the products and services within. The advent of underground shopping arcades, suburban malls, strip malls, power centres, elevated walkways and airports, overtook the urban street as the dominant, and arguably authentic urban experience that expressed visual consumption, and in turn social exchange and a vital public realm. Yonge Street's new crops of tall buildings (70+ storeys) offer very little newness programmatically to the street; one is underwhelmed by the nature of the massing that doesn't affect the street life. Instinctively, one feels that a significant scale change in and of itself warrants some change programmatically, as Sparke makes note of with The Truman Show as spectacle replaces true public interaction. 
Reimagining autonomous vehicles as part of the street mix may lead to changes on street level activity if the public expects an integration of their movement systems to include easy embark/disembark patterns along the street with AV. Street front addresses might respond to a lack of certain programs that aren't there if the public expects vital public realm activity. Street businesses will encourage passenger 'stops' and visits, and the problems of finding street parking may even one day vanish as we know them. The remainder of the paper will detail some of these ideas.

\section{PUBLIC REALM AND AV}

Slavo Žižek comments: 'it is often said that today, with our total exposure to the media, culture of public confessions and instruments of digital control, private space is disappearing. One should counter this commonplace with the opposite claim: it is the public space proper, which is disappearing' [40]. Žižek>s view of an eroded publicness due to constant surveillance and inability to escape is sounded to make us want to do something about it. Lyn H. Lofland writes in The Public Realm: Quintessential city life, that the use of the public realm, in physical spaces in the city operates as a series of properly scaled zones whereby the citizen, visitor and resident 'become not only a more mature political actor, but a more cosmopolitan' actor [41].

Lofland reminds us that the public realm, all realms are not defined by their physical shape and disposition; they are social territories [42] that are defined by the social events occurring there. She believes there are spaces that are public and that are 'inhospitable' because they do not contain a realm, only public space where interactions that permit 'uneventful interactions,' and that there are places linked to circulation that have an element of 'mild fear'-these have the right recipe in order to succeed as a true public realm and maintain its health.

Remaining sceptical that the virtual public won't successfully replace a placed (in shared 3D space) realm, Lofland maintains that strangers remain strangers because the interactions are 'between and among beings without bodies' [43]. If architecture may be defined as the symbolic representation of the power of a space, and that interiors represent the social human encounters that occupy a place (whether in architecture or a building), then Lofland's hope for an extended public realm with the changes wrought by AV can be appropriately scaled interiority that works in concert with the digital realm.

Martijn de Wall echoes Richard Sennett that we are in the midst of a technological revolution. He writes of a 'minimal cohesion' and 'maximum community' of a networked urbanism that de Waal sees as being a valid form of the public realm [44]. A network structure can build the types of valid forms of public realm that melds technology with physical space sympathetic to the type of active realm as defined in pioneering studies by Jane Jacobs and Lofland. Walter Benjamin warned that the problem with modern living was the loss of dwelling and 'given way to the porosity and transparency' of everything [45]. With the immense data gathering capabilities of AV's that can 'both consume and generate data' [46], drones, and our mobile devices alike, will require us to manage these new digital networking tools and try as best as we can to be vigilant to this new consumption model. Mark Kingwell suggests with a needed hopeful tone, that there really can be a crossover between individual needs and group needs that will be 'inexplicably joined' instead of in constant conflict [47].

An odd power exists today that didn't occur in the industrial revolution-there is choice that allows someone to cloak oneself with a 'membrane' [48] that occurs with the absolute freedom to construct a micro physical/virtual private sphere in the public and still be an active agent with a remote other. Might a form of sustainability that we seek and need to defend in the city be the sustainability of one's privacy? A realm of interiority that one is in fear of 
being lost in-with complicity with growing big data gathering in a world of an interiority of things amongst an IOT (Internet of Things).

Sometimes private virtual transactions yield new physical space; the growth of brick-andmortar storefronts that established online presences-such as Google and Amazon, have built stores to reconnect with a physical public space. The shopping experience has the potential for the unscripted and physical that is part of the public realm as defined by Lofland before [49]. This interiority, put in the context of 20 years time to grow the Internet suggests the start of new synergies between online and physical spaces. It is an example of how, by 'transforming their role' buildings have adapted to the digital situation of today. Farshid Moussavi explains how when addressing changes, it is going to be most successful at the micro level of built form and not the mega scale that will be the most impactful and it needs to engage culture when doing so [50].

Research points to people using their mobile device, eating, reading, watching films, and working as the most popular pastimes for passengers in driverless cars, according to a Carnegie Mellon University survey [51]. This transformation in how the public will expect to be able to use any micro space as they so choose is reminiscent of how the public has been using just about any public space as sites for private phone conversations and other personal activities. This will usher in a new era of how interiors will be consumed. Henry Ford did want his vehicles to be for the people-did that extend to how they might one day use the automobile too? Having choice of activity is a newer experience in automobiles. This will bring cascading challenges to strongly held ideas of the spatial field of automobiles-if the future of the once-private vehicle becomes a generic object, free from constantly updated fashion and styling, the vehicle might evolve in ways similar to the functional subway car seen as a generic container, free from the affected images in the hyper-advertising of the any-newcar free and untethered, unconnected in open space.

In 1969 the Metabolist Kisho Kurokawa was imagining a future mobile 'cyborg architecture,' that anticipated our connected present. He saw the future where everyone was in motion using 'a device which has become a living space in itself in the sense that man cannot hope to live elsewhere' [52]. This image of an evolution of Hall's extension transference is that space and vehicles are no longer tools-the inhabitant is free to do inside as he or she wishes. Compared to the affordances of a manually powered bicycle, some clever extensions and transformable adaptations can be surgically made (storage and foldable geometries, for example). A bicycle is a 'cold' tool that 'man moves by becoming one with the tool.' (my italics [53]) But the social spaces possible in a micro architecture of interiority that is a proto-room, a capsule if you will, is rich for designers to develop-the volume and rearrangement of seating is reimagined in the historic carriage and propelled in the future as AV cyborgs from the imagination of a Kurokawa.

Much as architecture has always been about the reactivation of its space, much like an old book or object [54] the addition to the city with micro-architecture that follows no prescribed programs that accentuates the potentialities of the city matrix with interior/exterior/interior pauses in a connected network can extend traditional institutions, dwellings, and human networks in positive ways for the city. The AV can be part of a public realm that is an open space for performance to occur. The influence of the work of Philosopher Judith Butlers' questioning of performativity whereby spaces are where identity is 'acted out' and open to transformation through the physical space by the actors present there and not dependent on the signs embedded in the space, architectural or otherwise imagines an interiority with agency that is about energy, flows, connections with others and the environment- it imagines a space less fixed in use and roles [55]. Compare to Koolhaas' question: 'Were not division, 
enclosure (i.e., imprisonment), and exclusion-which defined the wall's performance and explained its efficiency-the essential stratagems of any architecture?' [56] What might Butler's ideal architecture look like? What aspects of this new interiority would benefit from having some elements of fixity? And is energy the new threshold for such a space- between individuals, virtual and physical beings?

If we extend the idea of programs and the mobility that these afford to a future scenario, we can begin to imagine tectonically how the traditional quasi-systematized building elements of today made of sheet goods such as ply's, tubular extrusions, glass, metal channels in vehicles and mineral-based elements in buildings such as stone and concrete may be reworked with innovations of new materials that embody and redistribute energy and communicate in sustainable ways. Sean Lally, writes in The Air From Other Planets, how he anticipates a future interiority (and exteriority) whereby walls and the materials that make up space will have new levels of performativity that he calls 'material energies.' These new materials will be a fusion of how we experience space through our senses, and the traditional effects of materials in interiors, that shelter and provide beauty and comfort from the exterior [57]. Lally promotes a study of changing energy that wraps 'gradient boundaries of intensities' of particles and waves, coupled with alterations and 'chemical performance enhancers,' enabling someone to experience qualities of space that were hidden from their senses. Perception might be enhanced to sense fine particulates in the air that might be harmful on a smog day; a capacity to affect shape to work with the sun; form, texture, and temperature enlivens the solid-state of the container and builds a connection between the inhabitant with the volume and the outer volumes.

\section{CONCLUSION}

If there is no urbanity without a centre, as proposed by Henri Lefebvre [58] then that centre has to be continuously re-imagined and redefined not by the social dimensions of before but by what is to come. Paul Baran in the 1960's envisioned a different model of connection-he imagined a decentralized and distributed network that would become the Internet [59]. Our cities will need to be thought through differently if mitigating congestion, pollution and waste is a priority as well as building a generous network of urban realms in an autonomous space. The social, political and technological challenges of connecting spaces using AI, AV, IOT will be foundational for an extended mobility future that transforms how streets, their content/connections and all interiors will be used. Future sustainable practice of the always-on present will require solutions to energy use in order to reach one day a fully autonomous sustainable society. Incrementally we explore these spaces, first at the micro level of innovation-through fixed and mobile forms; and when useful they will be scaled-up in production that has moved beyond interiority that was once mass-produced and inert. Our well-intentioned mechanized environment is mobilizing towards a greater connectivity between its parts and the steady-state approach shifts to interiorities of multiple dimensions and zones.

\section{REFERENCES}

[1] Ladd, B., Autophobia: Love and Hate in the Automotive Age, University of Chicago Press: Chicago, p. 180, 2011.

[2] Sparke, P., The Modern Interior, Reaktion Books: London, pp. 15-17, 2008.

[3] Leach, N., Camouflage, The MIT Press: Cambridge, p. 2, 2006.

[4] Aicher, O., The World as Design (M. Robinson, Trans.), Ernst \& Sohn Verlag für Architektur: Berlin, pp. 143-149, 1994.

[5] Lally, S., The Air From Other Planets, Lars Muller Publishers: Zurich, p. 223, 2014. 
[6] Lally, S., Ibid, p. 160.

[7] Giedion, S., Mechanization Takes Command: A Contribution to Anonymous History, W. W. Norton \& Company Inc.: New York, 1975 (1948).

[8] Giedion, S., Ibid, pp. 79-86.

[9] Kingwell, M., Better Living: In Pursuit of Happiness from Plato to Prozac. The Virtues of Happiness, Penguin Books Toronto, pp. 283-313, 1999.

[10] Lipson, H. \& Kurman, M., Driverless: Intelligent Cars and the Road Ahead, The MIT Press: Cambridge, p. 253, 2016.

[11] Hall, E.T., The Hidden Dimension, Anchor Books: New York, p. 15, 1990.

[12] Hall, E.T., ibid, pp. 116-125.

[13] de Waal, M., The City as Interface, NAi010 publishers: Rotterdam, p. 19, 2014.

[14] The History of Car Phones, available at www.techwalla.com/articles/the-history-of-carphones (accessed 24 March 2017).

[15] Bell, J., Carchitecture: When the Car and the City Collide, August/Birkhauser: London, p. 21, 2001.

[16] Hall, E.T., Beyond Culture, Anchor Books: New York, 1989.

[17] Sennett, R., After Crisis - Contemporary Architectural Conditions, Architectural Papers V ETH Zurich. Craftsmanship: A Tool for Recovering the Materiality of the Physical Environment, ed. J.L. Mateo, Lars Müller Publishers: Baden, pp. 42-47, 2011.

[18] Dewdney, C., Last Flesh: Life in the Transhuman Era, Harper Collins: Toronto, 1998.

[19] Autonomous vehicles: challenges, opportunities, and future implications for transportation policies, available at www.link-springer-com.ezproxy.lib.ryerson.ca/article/10.100 7\%2Fs40534-016-0117-3 (accessed 5 January 2017)

[20] Smithson, R., The Writings of Robert Smithson, ed. N. Holt, New York University Press: New York, p. 79, 1979.

[21] Žižek, S., After Crisis - Contemporary Architectural Conditions, Architectural Papers V ETH Zurich, Architectural Parallax: Spandrels and Other Phenomena of Class Struggle, ed. J.L. Mateo, Lars Müller Publishers: Baden, pp. 94-101, 2011.

[22] The National Human Activity Pattern Survey (NHAPS): a resource for assessing exposure to environmental pollutants, available at www.nature.com/jes/journal/v11/n3/ full/7500165a.html?foxtrotcallback=true (accessed 17 November 2016)

[23] Žižek, S., Ibid, p. 96.

[24] Furman, A, Accommodating the cyclist in the city. The Sustainable City VIII: Urban Regeneration and Sustainability, WIT Press: Southampton and Boston, p. 8, 2014.

[25] The History of a City Underfoot, available at www.nytimes.com/2015/04/26/magazine/ the-history-of-a-city-underfoot.html (accessed 17 September 2016)

[26] Leach, N., Ibid.

[27] Sparke, P., Ibid, pp. 190-191.

[28] Sparke, P., Ibid, p. 212.

[29] Hall, E.T., The Hidden Dimension, Anchor Books: New York, p. 176, 1990.

[30] Reiman, J., Privacies: Philosophical Evaluations. Driving to the Panopticon: A Philosophical Exploration of the Risks to Privacy Posed by the Information Technology of the Future, ed. B. Rossler, Stanford University Press: Stanford, pp. 194-214, 2004.

[31] Meikle, G. \& Young, S., Media Convergence: Networked Digital Media in Everyday Life, Palgrave Macmillan: New York, pp. 148-171, 2012.

[32] Koolhaas, R., Mau, B. \& O.M.A., Small, Medium, Large, Extra-Large. Field Trip, ed. J. Sigler, The Monacelli Press: New York, pp. 215-232, 1995. 
[33] Vanderbil, T., Traffic: Why We Drive the Way We Do (and What it Says About Us), Vintage Books: New York, p. 196, 2009.

[34] Murray, S.C., Contemporary Curtain Wall Architecture, Princeton Architectural Press: New York, p. 25, 2009.

[35] Lofland, L.H., The Public Realm: Quintessential City Life, Aldine de Gruyter: New York, p. 16, 1998.

[36] Graham, D., Two-Way Mirror Power: selected writings by Dan Graham on his art. Dan Graham in Conversation with Brian Hatton, ed. Alexander Alberro, The MIT Press: Cambridge, pp. 144-154, 1999.

[37] Sunday Shopping, available at www.thecanadianencyclopedia.ca/en/article/sundayshopping/ (accessed 6 December 2016)

[38] Leong, S. T., Harvard Design School Guide to Shopping. Mobility, eds. C.J. Chung, J. Inaba, R. Koolhaas \& S.T. Leong, Taschen: New York, p. 447, 2001.

[39] City of Toronto, Fire Insurance Plans 1894, available at www1.toronto.ca/wps/portal/contentonly?vgnextoid=c944f9da1497c510VgnVCM10000071d60f89RCRD (accessed 15 January 2017)

[40] Žižek, S., Event, Penguin Random House: UK, p. 177, 2015.

[41] Lofland, Ibid, p. 242.

[42] Lofland, Ibid, p. 244.

[43] Lofland, Ibid, p. 249.

[44] de Waal, M., Ibid, pp. 174-176.

[45] Leach, N., Ibid, p. 18.

[46] Lipson, H. \& Kurman, M., Ibid, pp. 237-240.

[47] Kingwell, M., Ibid, p. 306.

[48] de Waal, M., Ibid, p. 19.

[49] Amazon just confirmed its 10th bookstore, signalling this is way more than an experiment, available at www.recode.net/2017/3/8/14850324/amazon-books-store-bellevuemall-expansion (accessed 20 March 2017).

[50] Moussavi, F., The Function of Style, ed. M. Ciancarella, J.A. Scelsa, M. Crettier, K. Kilalea), Harvard University Graduate School of Design, Functionlab, Actar: Lexington, p. 35, 2014.

[51] Lipson, H. \& Kurman, M., Ibid, p. 274.

[52] De Cauter, L., Reflect \#3 The Capsular Civilization, On the City in the Age of Fear, NAi Publishers: Rotterdam, p. 65, 2004.

[53] De Cauter, L., Ibid, p. 79.

[54] Leach, N., Ibid, pp. 179-180.

[55] Smitheram, J., Spatial performativity/spatial performance. Architectural Theory Review, 16(1), pp. 60-61, 2011. https://doi.org/10.1080/13264826.2011.560387

[56] Koolhaas, R., Ibid.

[57] Lally, S., Ibid, pp. 95, 15-16.

[58] Lefebvre, H., Writings on Cities. No Salvation away from the Centre? Blackwell Publishers: Oxford, pp. 205-208, 1996.

[59] Gorbis, M., The Nature of the Future: dispatches from the socialstructed world, Free Press: New York, p. 23, 2013. 